\title{
Long-term exposure to air pollution and asthma hospitalisations in older adults: a cohort study
}

\author{
Zorana Jovanovic Andersen, ${ }^{1}$ Klaus Bønnelykke, ${ }^{2}$ Martin Hvidberg, ${ }^{3}$ Steen S Jensen, ${ }^{3}$ \\ Matthias Ketzel, ${ }^{3}$ Steffen Loft, ${ }^{4}$ Mette Sørensen, ${ }^{1}$ Anne Tjønneland, ${ }^{1}$ Kim Overvad, ${ }^{5,6}$ \\ Ole Raaschou-Nielsen ${ }^{1}$
}

\section{See Editorial, p 2}

- Additional materials are published online only. To view these files please visit the journal online (http://thorax.bmj. com/content/67/1.toc).

${ }^{1}$ Institute of Cancer Epidemiology, Danish Cancer Society, Copenhagen, Denmark ${ }^{2}$ Copenhagen Prospective Studies on Asthma in Childhood, Health Sciences, University of Copenhagen, Copenhagen University Hospital, Gentofte, Copenhagen, Denmark

${ }^{3}$ National Environmental Research Institute, Aarhus University, Roskilde, Denmark ${ }^{4}$ Department of Environmental Health, University of Copenhagen, Copenhagen, Denmark

${ }^{5}$ School of Public Health, Aarhus University, Aarhus, Denmark ${ }^{6}$ Centre for Cardiovascular Research, Aalborg Hospital, Aarhus University Hospital, Aalborg, Denmark

\section{Correspondence to}

Dr Zorana J Andersen, Institute of Cancer Epidemiology, Danish Cancer Society,

Strandboulevarden 49

Copenhagen 2100, Denmark zorana@cancer.dk

Received 21 January 2011 Accepted 19 July 2011 Published Online First 2 September 2011

\section{ABSTRACT}

Background Exposure to air pollution in early life contributes to the burden of childhood asthma, but it is not clear whether long-term exposure to air pollution can lead to asthma onset or progression in adulthood.

Objectives The authors studied the effect of exposure to traffic-related air pollution over 35 years on the risk for asthma hospitalisation in older people.

Methods 57053 participants in the Danish Diet, Cancer and Health cohort, aged 50-65 years at baseline (1993-1997), were followed up for first hospital admission for asthma until 2006, and the annual nitrogen dioxide $\left(\mathrm{NO}_{2}\right)$ levels were estimated as a proxy of the exposure to traffic-related air pollution at the residential addresses of the participants since 1971. The association between $\mathrm{NO}_{2}$ and hospitalisation for asthma was modelled using Cox regression, for the full cohort and in people with and without previous hospitalisations for asthma, and the effect modification by comorbid conditions was assessed.

Results During 10.2 years' median follow-up, 977 $(1.9 \%)$ of 53695 eligible people were admitted to hospital for asthma: 821 were first-ever admissions and 176 were readmissions. $\mathrm{NO}_{2}$ levels were associated with risk for asthma hospitalisation in the full cohort (HR and $95 \% \mathrm{Cl}$ per IOR, $\left.5.8 \mu \mathrm{g} / \mathrm{m}^{3}: 1.12 ; 1.04-1.22\right)$, and for first-ever admissions $(1.10 ; 1.01-1.20)$, with the highest risk in people with a history of asthma $(1.41 ; 1.15-2.07)$ or chronic obstructive pulmonary disease (COPD) (1.30; 1.07-1.52) hospitalisation.

Conclusions Long-term exposure to traffic-related air pollution increases the risk for asthma hospitalisation in older people. People with previous asthma or COPD hospitalisations are most susceptible.

\section{INTRODUCTION}

Asthma prevalence is increasing in high-income countries, ${ }^{1}$ including Denmark, where an increase in the severity of adult asthma has been documented. ${ }^{2}$ The prevalence of asthma in older adults is $6-10 \%$ in high-income countries, ${ }^{3}$ and the economic burden associated with hospital care, medications and years of work lost due to morbidity and mortality is substantial. ${ }^{4}$ This burden is projected to escalate with the increase in the number of older people with asthma due to enhanced longevity. ${ }^{3}$ Asthma management among older people has traditionally focused on diagnosis and treatment. ${ }^{5}$ A comprehensive approach to asthma control in older people should pay

\section{Key messages}

What is the key question?

- Does prolonged living in areas with high air pollution levels cause asthma onset in elderly adults?

What is the bottom line?

- Long-varying exposure to traffic-related air pollution in adult life can give asthma.

Why read on?

- To find out that people with prior chronic lung disease, in terms of asthma or COPD are most susceptible to the effects of air pollution.

special attention to preventing asthma exacerbations, the main determinants of disease severity and costs. ${ }^{6}$

Air pollution from traffic is ubiquitous in urban environments, as it affects millions of people, and it has been extensively studied in relation to childhood asthma. Despite mixed evidence, ${ }^{7}$ recent data indicate that air pollution plays an important role in the burden of asthma in children. ${ }^{89}$ It is not known how long-term exposure to air pollution affects asthma in older adults, another susceptible population, partly due to a lack of data from cohorts of older people.

Evidence linking chronic exposure to air pollution and adult asthma is based on studies with selfreported asthma prevalence ${ }^{10}$ and incidence, ${ }^{11-14}$ which typically lack information on residential address history, and define long-term exposure to air pollution as a single-year level of nitrogen dioxide $\left(\mathrm{NO}_{2}\right)$ at recruitment ${ }^{12}$ or follow-up. ${ }^{11}{ }^{13}$ In a Swiss cohort study, the cumulative levels of modelled traffic-related particulate matter $<10 \mu \mathrm{m}$ in diameter over 11 years were associated with asthma incidence, but only in non-smokers. ${ }^{14}$ The same cohort linked improvements in air pollution levels over 11 years to attenuation of the decline in lung function ${ }^{15}$ and reduced rates of respiratory symptoms, ${ }^{16}$ providing important clues about the causality between long-term air pollution exposures and chronic respiratory disease.

We studied the association between weighted mean $\mathrm{NO}_{2}$ concentration at the residence over 35 years and the risk for hospital admission for asthma in a Danish cohort of older people. 


\section{METHODS}

\section{Design and health outcome}

The Danish Diet, Cancer and Health cohort ${ }^{17}$ consists of 57053 people from Copenhagen or Aarhus aged 50-65 years at baseline (1993-1997) from whom information on diet, education, occupation and lifestyle was obtained using questionnaires. We linked the Diet, Cancer and Health cohort to: the Danish Hospital Discharge Register, dating back to 1976, to identify hospital admissions for asthma (ICD-10: J45-46), chronic obstructive pulmonary disease (COPD) (J40-44), ischaemic heart disease (I20-25) and stroke (I60-63); the Danish Diabetes Register to obtain the date of onset of diabetes; the Central Population Registry to obtain date of death, emigration and residential address history (1971-2006). We defined our primary outcome as the first hospital admission for asthma between baseline (1993-1997) and 2006 for the whole cohort, and additionally studied separately the first-ever asthma hospitalisation, in people without an asthma hospitalisation before baseline, and rehospitalisation for asthma, in people with asthma hospitalisations before baseline. Comorbidity with COPD, ischaemic heart disease, stroke or diabetes was defined prior to admission for asthma.

\section{Exposure assessment}

The Danish AirGIS dispersion modelling system ${ }^{18}$ (described in the online supplement) was used to model outdoor mean annual concentrations of $\mathrm{NO}_{2}$ at the residential addresses since 1971 of the cohort members with an $80 \%$ or better residential history ( $97.6 \%$ of the cohort). Missing values due to missing address or missing geographical coordinates were substituted by the levels calculated for the preceding address or, when the first address was missing, for the subsequent address. We thus obtained a complete series of annual mean $\mathrm{NO}_{2}$ concentrations at the residential addresses of each cohort member since 1971, with an average of the 35-year weighted mean $\mathrm{NO}_{2}$ levels, which is the main exposure metric used in this study.
We defined shorter exposure windows with $\mathrm{NO}_{2}$ : 15-year mean (since 1991), 1-year mean at baseline and 1-year mean at the follow-up; and proxies based on traffic proximity at baseline residence: the presence of a major road (density $\geq 10000$ vehicles/day) within a 50 or $100 \mathrm{~m}$ radius and traffic load (total kilometres driven by vehicles) within a $200 \mathrm{~m}$ radius.

\section{Statistical methods}

We applied the Cox proportional hazards model to study the association between hospital admission for asthma and exposure to $\mathrm{NO}_{2}$, with age as the underlying time, event at age at admission for asthma, and censoring at date of death, emigration or 27 June 2006, which ever came first. Models were adjusted for a priori defined confounders, in three steps: (1) age; (2) also including smoking status, duration and intensity, and environmental tobacco smoke at home or work; and (3) also including gender, occupational exposure, obesity and educational level, all defined as in table $1 . \mathrm{NO}_{2}$ levels were log-transformed and modelled as a time-dependent variable. Estimates were presented per IOR. Occupational exposure was defined as working in industries linked to occupational asthma ${ }^{19}$ from a list of selfreported occupations. The effect modification of an association between $\mathrm{NO}_{2}$ and asthma hospitalisation by baseline characteristics and comorbid conditions was evaluated by introducing interaction terms into the model and tested by the Wald test. The results are presented as HRs with $95 \%$ CIs, estimated using Proc PHREG, SAS V.9.2. The dose-response function was produced using a restricted cubic spline in the plot.design function of the $\mathrm{R}$ statistical software.

\section{RESULTS}

Of the 57053 people in the cohort, we excluded 571 with a cancer diagnosis before baseline, 962 with missing baseline residential address, 1236 with $<80 \%$ residential address history available (1971 to end of follow-up) and 589 with missing information on covariates. Of the remaining 53695 people, 977

Table 1 Characteristics of the Diet, Cancer and Health cohort $(n=53695)$ by first asthma hospitalisation status at follow-up for full cohort

\begin{tabular}{|c|c|c|c|c|}
\hline & Total $n=53695$ & No asthma $n=52698$ & Asthma $n=997$ & $\mathrm{HR}^{*}(95 \% \mathrm{Cl})$ \\
\hline \multicolumn{5}{|l|}{ Baseline cohort covariates } \\
\hline Mean (SD) age (years) & $56.7(4.4)$ & $56.7(4.4)$ & $57.3(4.5)$ & $1.04(1.02$ to 1.05$)$ \\
\hline Males $n(\%)$ & $25575(47.6)$ & $25190(47.8)$ & $385(38.6)$ & $0.71(0.62$ to 0.80$)$ \\
\hline Previously smoked $n(\%)$ & $15362(28.6)$ & $15044(28.5)$ & $318(31.9)$ & $1.30(1.11$ to 1.52$)$ \\
\hline Currently smoke $n(\%)$ & $19347(36.0)$ & $18977(36.0)$ & $370(37.1)$ & $1.19(1.02$ to 1.38$)$ \\
\hline Mean (SD) smoking duration (years) & $19.0(17.2)$ & $19.0(17.2)$ & $21.3(17.4)$ & $1.08(1.05$ to 1.12$)$ \\
\hline Occupational exposure $n(\%)$ & $19502(36.3)$ & $19105(36.2)$ & $397(39.8)$ & $1.15(1.01$ to 1.32$)$ \\
\hline Obese $\left(\mathrm{BMI} \geq 30 \mathrm{~kg} / \mathrm{m}^{2}\right) n(\%)$ & $7808(14.5)$ & $7627(14.5)$ & $181(18.1)$ & $1.31(1.11$ to 1.53$)$ \\
\hline$<8$ years of education $n(\%)$ & $17763(33.1)$ & $17393(33.0)$ & $370(37.1)$ & 1.00 \\
\hline $8-10$ years of education $n(\%)$ & $24768(46.1)$ & $24325(46.2)$ & $443(44.4)$ & $0.86(0.75$ to 0.99$)$ \\
\hline$\geq 10$ years of education $n(\%)$ & $11164(20.8)$ & $10980(20.8)$ & $184(18.5)$ & $0.80(0.67$ to 0.95$)$ \\
\hline Ischaemic heart disease (I20-25) $n(\%)$ & $5457(10.2 \%)$ & $5362(10.2 \%)$ & $95(9.5 \%)$ & $0.94(0.76$ to 1.16$)$ \\
\hline Stroke $(160-163) n(\%)$ & $2542(4.7 \%)$ & $2520(4.8 \%)$ & $22(2.2 \%)$ & $0.46(0.30$ to 0.69$)$ \\
\hline Diabetes $\neq n(\%)$ & $5340(9.9 \%)$ & $5213(9.9 \%)$ & $127(12.7 \%)$ & $1.30(1.08$ to 1.57$)$ \\
\hline
\end{tabular}

*Cox proportional hazards model univariate effect of each covariate/comorbid condition in 'Asthma' versus 'No asthma' columns.

†For comorbid conditions identified in the Danish Hospital Discharge register as hospitalisations prior to asthma hospitalisation.

¥ldentified in the Danish Diabetes Register.

$\mathrm{BMI}$, body mass index; COPD, chronic obstructive pulmonary disease. 


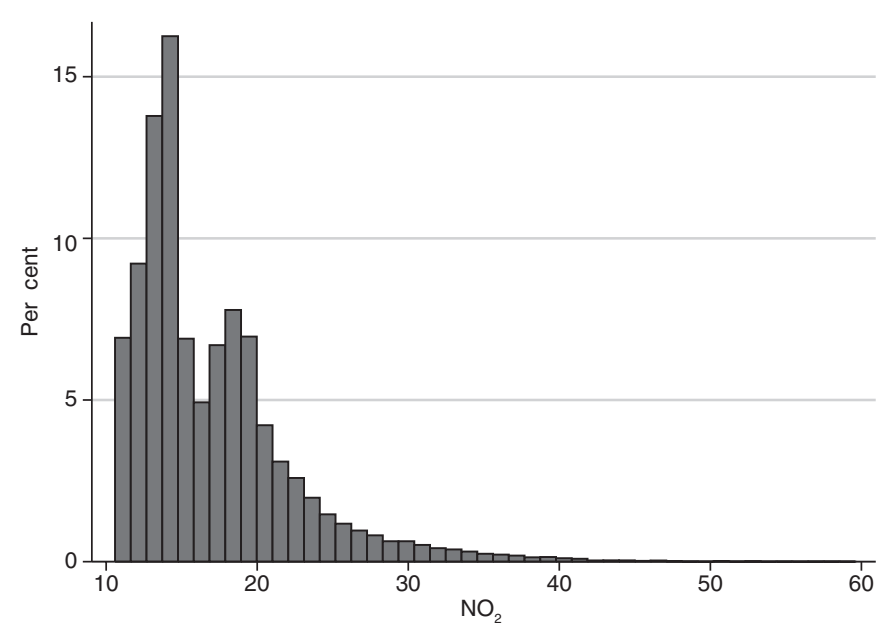

Figure 1 Distribution of the estimated mean levels of nitrogen dioxide $\left(\mathrm{NO}_{2}\right)$ at residence for the 53695 Diet, Cancer and Health cohort members.

(1.9\%) had a first hospital admissions for asthma between baseline (1993-1997) and 2006, over 10.2 years' median followup (533 234 person-years). Of the 53143 people without asthma hospitalisation before baseline, $821(1.5 \%)$ had a first hospitalisation over 10.2 years' median follow-up (528 940 person-years). Of the 552 people hospitalised for asthma before baseline, 176 (31.9\%) were readmitted for asthma, over 9.5 years' median follow-up (4294 person-years). Of the 53695 people, 37836 $(70.5 \%)$ did not change their address between baseline and the end of follow-up (non-movers).

Women were more often admitted to hospital for asthma (table 1). Current and previous active smoking, passive smoking, employment in occupations related to asthma and obesity were significantly associated with an increased risk, while medium and high educational levels were associated with a reduced risk for asthma hospitalisation (table 1). Patients with COPD and diabetes were significantly more, whereas patients with stroke were less likely to be hospitalised for asthma than persons without these comorbid conditions.

The estimated $\mathrm{NO}_{2}$ levels varied widely (figure 1) with a median of 15.2 and IOR $5.8 \mu \mathrm{g} / \mathrm{m}^{3}$, and were higher in the 997 asthma cases $\left(16.4\right.$ and $\left.6.3 \mu \mathrm{g} / \mathrm{m}^{3}\right)$. The distribution of alternative traffic proxies is shown in online supplementary table W1.

We found significant positive associations between $\mathrm{NO}_{2}$ level and first hospital admission in the full cohort (HR per IOR $\left.5.8 \mu \mathrm{g} / \mathrm{m}^{3}: 1.12 ; 1.04-1.22\right)$, which was insensitive to choice of confounders (table 2). The associations were similar for the firstever asthma hospitalisation (1.10; 1.01-1.20), but markedly higher for rehospitalisation in people with a previous asthma hospitalisation $(1.41 ; 1.15-1.71) \quad(p=0.05$, Wald test for interaction). The associations indicated a dose-response relationship (figure 2): cohort members living in areas with high (upper quartile) air pollution levels have a significantly higher risk for asthma hospitalisation (30\% for first admission and $87 \%$ for readmission) than those living in areas with low air pollution levels (lower quartile) (table 2). Sensitivity analyses in the full cohort showed significant or borderline significant associations with alternative definitions of $\mathrm{NO}_{2}$ with $\mathrm{HR}$ of 1.11 (1.03-1.20) for the 15-year (since 1971) mean, 1.08 (1.00-1.17) for the 1 -year mean at baseline (1993-1997) and 1.18 (1.09-1.28) for the 1-year mean at follow-up (asthma admission), and similar results with the first-ever hospitalisations and rehospitalisations (online supplementary table W2). No associations were detected with traffic proximity proxies at baseline residence in non-movers (online supplementary table W2).

The risk for asthma hospitalisation associated with $\mathrm{NO}_{2}$ was four times higher in people with previous COPD hospitalisations $(1.30 ; 1.07-1.52)$, with significant effect modification $(\mathrm{p}=0.04)$.

Our results were not sensitive to the inclusion of the time under study in the model as a non-parametric term, in order to adjust for possible secular changes in air pollution over the follow-up time.

\section{DISCUSSION}

The risk for asthma hospitalisation in this cohort of older people was significantly positively associated with increasing levels of $\mathrm{NO}_{2}$ assessed over 35 years at their residences, and was most pronounced for people with a previous asthma or COPD hospitalisation.

This is the first study to relate the hospital admission for asthma to long-term exposure to air pollution. Our results are

Table 2 Association between exposure to nitrogen dioxide $\left(\mathrm{NO}_{2}\right)$ and first asthma hospital admission after baseline (1993-1997) in the Diet, Cancer and Health cohort

\begin{tabular}{|c|c|c|c|c|}
\hline Population & $\mathrm{NO}_{2}\left(\right.$ IOR $\left.5.8 \mu \mathrm{g} / \mathrm{m}^{3}\right)$ & $\begin{array}{l}\text { Adjusted for age } \\
\text { HR (95\%CI) }\end{array}$ & $\begin{array}{l}\text { Adjusted for age and smoking* } \\
\text { HR }(95 \% \mathrm{CI})\end{array}$ & $\begin{array}{l}\text { Fully adjusted } \dagger \\
\text { HR }(95 \% \mathrm{CI})\end{array}$ \\
\hline \multirow[t]{5}{*}{ Full cohort, $n=53695$} & Linear trend & 1.15 (1.06 to 1.24$)$ & 1.14 (1.05 to 1.23$)$ & $1.12(1.04$ to 1.22$)$ \\
\hline & $<13.4 \mu \mathrm{g} / \mathrm{m}^{3}$ & 1.00 & 1.00 & 1.00 \\
\hline & $13.4-15.2 \mu \mathrm{g} / \mathrm{m}^{3}$ & $1.30(1.08$ to 1.58$)$ & $1.29(1.07$ to 1.56$)$ & $1.28(1.05$ to 1.54$)$ \\
\hline & $15.2-19.2 \mu \mathrm{g} / \mathrm{m}^{3}$ & $1.23(1.02$ to 1.50$)$ & $1.21(1.00$ to 1.47$)$ & $1.20(0.99$ to 1.46$)$ \\
\hline & $\geq 19.2 \mu \mathrm{g} / \mathrm{m}^{3}$ & $1.43(1.19$ to 1.72$)$ & 1.41 (1.17 to 1.69$)$ & $1.38(1.14$ to 1.66$)$ \\
\hline \multirow{5}{*}{$\begin{array}{l}\text { No asthma hospitalisation before } \\
\text { baseline, } n=53143\end{array}$} & Linear trend & $1.13(1.03$ to 1.23$)$ & 1.12 (1.02 to 1.22$)$ & $1.10(1.01$ to 1.20$)$ \\
\hline & $<13.4 \mu \mathrm{g} / \mathrm{m}^{3}$ & 1.00 & 1.00 & 1.00 \\
\hline & $13.4-15.2 \mu \mathrm{g} / \mathrm{m}^{3}$ & $1.23(1.00$ to 1.51$)$ & $1.22(0.99$ to 1.50$)$ & $1.20(0.97$ to 1.48$)$ \\
\hline & $15.2-19.2 \mu \mathrm{g} / \mathrm{m}^{3}$ & $1.18(0.95$ to 1.45$)$ & $1.16(0.94$ to 1.43$)$ & $1.14(0.93$ to 1.41$)$ \\
\hline & $\geq 19.2 \mu \mathrm{g} / \mathrm{m}^{3}$ & 1.36 (1.11 to 1.66$)$ & 1.33 (1.09 to 1.63$)$ & 1.30 (1.06 to 1.59$)$ \\
\hline \multirow{5}{*}{$\begin{array}{l}\text { History of asthma hospitalisation before } \\
\text { baseline, } n=552\end{array}$} & Linear trend & $1.40(1.15$ to 1.70$)$ & 1.39 (1.13 to 1.67$)$ & 1.41 (1.15 to 1.71$)$ \\
\hline & $<13.4 \mu \mathrm{g} / \mathrm{m}^{3}$ & 1.00 & 1.00 & 1.00 \\
\hline & $13.4-15.2 \mu \mathrm{g} / \mathrm{m}^{3}$ & 1.35 (0.83 to 2.18$)$ & 1.35 (0.83 to 2.19$)$ & 1.28 (0.79 to 2.07$)$ \\
\hline & $15.2-19.2 \mu \mathrm{g} / \mathrm{m}^{3}$ & $1.41(0.86$ to 2.31$)$ & $1.38(0.84$ to 2.26$)$ & $1.32(0.80$ to 2.18$)$ \\
\hline & $\geq 19.2 \mu \mathrm{g} / \mathrm{m}^{3}$ & $1.90(1.19$ to 3.05$)$ & 1.84 (1.15 to 2.96$)$ & 1.87 (1.16 to 3.02$)$ \\
\hline
\end{tabular}




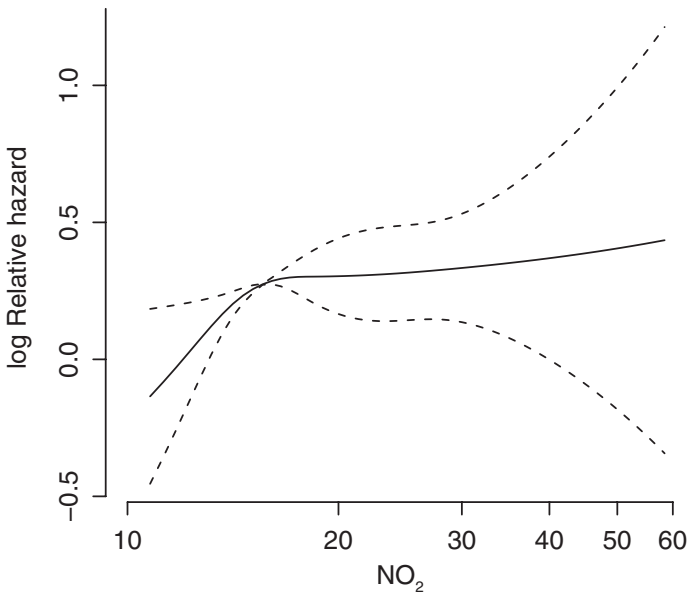

Figure 2 Association between exposure to nitrogen dioxide $\left(\mathrm{NO}_{2}\right)$ levels at residence and asthma hospitalisation (log relative hazard with $95 \% \mathrm{Cl})$ for the 53695 Diet, Cancer and Health cohort members, adjusted for smoking status (never, previous, current), smoking intensity, smoking duration, environmental tobacco smoke, occupational exposure, gender, body mass index and educational level.

generally in agreement with those of asthma prevalence ${ }^{10}$ and incidence, ${ }^{11-14}$ but formal comparisons are limited due to different definitions of asthma and air pollution exposure. Whereas doctor-diagnosed asthma was used as an outcome in a single study, ${ }^{11}$ others relied on self-reports. ${ }^{10}{ }^{12-14}$ Asthma is a chronic disease of complex phenotype and recurring symptoms, and it is difficult to define its presence or absence at a definite point of time or to identify its time of onset. ${ }^{20}$ The rates of self-reported asthma depend on awareness of asthma in the population studied ${ }^{1}$ and are, especially in epidemiological surveys specifically of respiratory disease, ${ }^{10}{ }^{12-14}$ subject to recall and information bias. Similarly, the self-reported onset of asthma is often loosely defined and subject to recall bias. ${ }^{11-14}$ Overdiagnoses of asthma by primary care physicians, estimated at about $30 \%{ }^{21}$ is another source of bias, due to the widespread practice of symptoms-based diagnosis without objective measurements of reversible airflow obstruction. Hence, the use of an objective measure of asthma by means of hospital admission from a nationwide register is appealing. Asthma requiring hospital admission is mainly at the severe end of the disease spectrum and is traditionally confirmed by objective measurements of lung function and reversible airflow obstruction in Danish hospitals. The specificity of asthma diagnoses in the Danish Hospital Discharge Register was found to be as high as $0.98,{ }^{22}$ validating their use in epidemiological studies.

An important limitation of this study is that asthma hospitalisation is not an accurate marker of asthma onset and underrepresents the real asthma burden, as asthma often remains undiagnosed for many years and only a fraction of asthma patients are hospitalised. Rather, the first hospitalisation for asthma should be regarded as a hallmark of asthma progression to a more severe stage or exacerbation. Owing to the lack of selfreports of asthma, we were not able to define the incidence of asthma in this cohort.

Assigning individual exposure to air pollution with high spatial (address-specific) and temporal (annual mean) resolution and assessment over 35 years is a novel approach. Typically, single-year mean $\mathrm{NO}_{2}$ levels were assigned at the residential address at recruitment ${ }^{10}{ }^{11}$ or follow-up, ${ }^{12}{ }^{13}$ neither of which captured the dynamics of the exposure history. Furthermore, higher risk estimates were observed in non-movers, ${ }^{13}{ }^{14}$ suggesting that greater precision in exposure assignment would improve the chances of detecting associations with asthma. We found significant positive associations for asthma admissions with all definitions of the mean $\mathrm{NO}_{2}$ reflecting different exposure windows, detecting almost identical but slightly smaller HRs with the 15-year mean (since 1991) $(1.11 ; 1.03-1.20)$ than with 35-year mean (since 1971) $(1.12 ; 1.04-1.22)$, attenuated HRs with the 1-year mean at baseline $(1.08 ; 1.00-1.17)$ and enhanced HRs with 1-year mean at the follow-up (1.18; 1.09-1.28) (online supplementary table W2). Correlation between the 35-year mean (since 1971) and the 15-year mean (since 1991) and the 35-year mean and the 1-year mean at the follow-up, respectively, was high (correlation coefficient $r=0.92$ and 0.88 ). It is likely that the performance of the dispersion model estimating $\mathrm{NO}_{2}$ levels was poorer longer back in time, owing to the higher uncertainty of model input data such as emission factors and traffic counts. Thus, we cannot discern whether the stronger associations with $\mathrm{NO}_{2}$ levels at follow-up, when compared with the 35-, 15- and 1-year means at baseline, reflect the relevance of more recent exposures for asthma hospitalisation or merely the better performance of the dispersion model in more recent years. However, we found no significant associations with traffic proximity proxies at baseline residence (online supplementary table $\mathrm{W} 2$ ), implying that these naive surrogates of long-term exposure to air pollution are inferior to the modelled levels of $\mathrm{NO}_{2}$, as observed earlier, ${ }^{14}$ and that the modelled air pollution exposure was a likely condition for detecting associations in this study.

We were not able to estimate early-life exposures to air pollution in this cohort, and do not know how these relate to adult-life exposures and how much their inclusion would affect our estimates. Early-life exposures have an adverse effect on asthma in childhood, ${ }^{7-9}$ but no data have yet examined the relevance of life-time exposures on the risk for asthma in adulthood.

We cannot conclude from our data whether traffic-generated gas and airway irritant $\mathrm{NO}_{2}{ }^{23}$ are relevant agents or merely indicators of other traffic-related pollutants, such as particulate matter. Stronger evidence suggests that particulate matter capable of triggering inflammation and inducing oxidative stress ${ }^{24}$ may be a responsible agent. Studies on humans in exposure chambers ${ }^{25}$ and of real-life exposures ${ }^{26}$ illustrated that diesel exhaust can provoke increased airway resistance and bronchial inflammatory changes. Repeated inhalation injury of lung tissues by long-term exposure to air pollution is believed to be central to the exacerbation of asthma. ${ }^{24}$ However, some of the observed effects could possibly be ascribed to the short-term effects of increases in air pollution on the days prior to asthma admission, ${ }^{27}$ which, perhaps in synergy with accumulated chronic effects, provoke asthma exacerbation. Discerning acute from chronic effects of air pollution on asthma is important to understand the underlying mechanisms and warrants more studies in cohorts with available daily measurements and individual level air pollution data.

The association between $\mathrm{NO}_{2}$ and asthma hospitalisations was strongest among previous and current smokers and people exposed to environmental tobacco smoke (table 3), in agreement with Jacquemin et $a l^{13}$ and in contrast to Künzli et $a l^{14}{ }^{14}$ who detected associations between air pollution and asthma only in non-smokers. We cannot exclude the possibility that the observed results reflect misclassification of asthma as COPD, which is more strongly related to smoking than asthma, or residual confounding in our estimates due to inadequate adjustment for smoking; however, this is unlikely, as in other studies of this cohort smoking has shown the expected associations with $\mathrm{COPD}^{28}$ and lung cancer, ${ }^{29}$ indicating that the data 
Table 3 Modification of associations* between $\mathrm{NO}_{2}$ (per IQR of $5.8 \mu \mathrm{g} / \mathrm{m}^{3}$ ) and first asthma hospital admissions $(\mathrm{n}=977$ ) by baseline characteristics and comorbid conditions among the 53695 Diet, Cancer and Health cohort participants

\begin{tabular}{|c|c|c|c|c|c|}
\hline Covariates & Covariate level & $\mathbf{n}$ & Hospitalisation rate $†$ & HR $(95 \%$ CI) & p Value $\neq$ \\
\hline \multirow[t]{2}{*}{ Gender } & Male & 385 & 1.5 & $1.19(0.97$ to 1.40$)$ & 0.30 \\
\hline & Female & 612 & 2.2 & 1.09 (0.99 to 1.19$)$ & \\
\hline \multirow[t]{3}{*}{ Smoking status } & Never & 309 & 1.6 & $1.05(0.90$ to 1.20$)$ & 0.31 \\
\hline & Previous & 318 & 2.1 & $1.17(0.88$ to 1.47$)$ & \\
\hline & Current & 370 & 1.9 & $1.15(0.85$ to 1.43$)$ & \\
\hline \multirow[t]{2}{*}{ ETS } & Yes & 686 & 2.0 & $1.16(0.88$ to 1.44$)$ & 0.24 \\
\hline & No & 311 & 1.6 & $1.04(0.89$ to 1.19$)$ & \\
\hline \multirow[t]{2}{*}{ Occupational exposure } & Yes & 390 & 2.3 & $1.07(0.85$ to 1.28$)$ & 0.28 \\
\hline & No & 607 & 1.6 & $1.17(1.06$ to 1.27$)$ & \\
\hline \multirow[t]{2}{*}{$\operatorname{COPD}(n=2139)$} & Yes & 219 & 11.0 & $1.30(1.07$ to 1.52$)$ & 0.04 \\
\hline & No & 778 & 1.5 & 1.07 (0.98 to 1.17$)$ & \\
\hline \multirow[t]{2}{*}{ IHD $(n=5458)$} & Yes & 91 & 1.8 & $1.00(0.70$ to 1.30$)$ & 0.35 \\
\hline & No & 901 & 1.9 & 1.14 (1.06 to 1.22$)$ & \\
\hline \multirow[t]{2}{*}{ Stroke $(\mathrm{n}=2542)$} & Yes & 22 & 0.9 & $0.86(0.27$ to 1.46$)$ & 0.36 \\
\hline & No & 975 & 1.9 & $1.13(1.05$ to 1.21$)$ & \\
\hline \multirow[t]{2}{*}{ Diabetes $(n=5283)$} & Yes & 72 & 1.3 & $0.87(0.53$ to 1.21$)$ & 0.08 \\
\hline & No & 925 & 1.9 & $1.15(1.07$ to 1.23$)$ & \\
\hline
\end{tabular}

*Fully adjusted for smoking status (never, previous, current), smoking intensity, smoking duration, ETS, occupational exposure, gender, body mass index and educational level. †Crude hospitalisation rate per 1000 person-years.

\#For Wald test for interaction.

COPD, chronic obstructive pulmonary disease; ETS, environmental tobacco smoke; IHD, ischaemic heart disease; $\mathrm{NO}_{2}$, nitrogen dioxide.

on smoking are of high quality. Our results rather suggest modification of the effect of air pollution by smoking, hinting at additive harmful effects of smoking and air pollution on asthma. The biological plausibility of the additive effects of synergistic exposure to tobacco and air pollution particles on asthma is supported by a study showing more rapid loss of lung function in smokers with asthma than in non-smokers with asthma. ${ }^{30}$ Künzli et al $^{14}$ attributed the lack of an effect in smokers due to a very marginal contribution of air pollution to the development of asthma in smokers. These conflicting results merit more research on the effects of joint exposures to air pollution and tobacco smoke on asthma development and progression.

We found a threefold to fourfold enhancement in the effects of exposure to $\mathrm{NO}_{2}$ on asthma admissions among people with previous asthma or COPD hospitalisation, respectively, when compared with those without chronic lung disease. Although asthma and COPD have distinct risk factors and clinical phenotypes, establishing a clear separation between the two is difficult. They are both inflammatory disorders, and often coexist, with both chronic and reversible airway obstruction being present, resulting in misdiagnoses of the two conditions. ${ }^{31}$ Although objectively measured lung function is required for discharge diagnoses of asthma and COPD, and reversible airway obstruction is usually required for a discharge diagnosis of asthma in Danish hospitals, it is likely that some of the asthma patients in this study also had an irreversible component of airway obstruction. Previously, we have found slightly weaker associations between $\mathrm{NO}_{2}$ and first-ever COPD hospital admission to that observed with first-ever asthma admission in this study, ${ }^{28}$ implying comparable effects of long-term exposures of air pollution on both COPD and asthma. Finally, the observed associations in this study were not sensitive to the exclusion of 452 people with COPD hospitalisations before baseline (HR for the 35-year $\mathrm{NO}_{2}$ mean: $1.11(1.02-1.21)$ in the full cohort, 1.10 $(1.01-1.21)$ and $1.29(1.03-1.60)$ in those without and with asthma hospitalisations before baseline, respectively).

Our results suggest that air pollution exacerbates asthma leading to rehospitalisation in those with prior asthma or COPD hospitalisations to a greater extent than it causes new asthma hospitalisations. Increasing susceptibility with age, due to accel- erated loss of lung function, ${ }^{30}$ and increasing prevalence of asthma and comorbid conditions ${ }^{3}$ including COPD suggest that the effect of air pollution is even greater in the oldest of the older people.

We lacked data on the familial history of asthma and atopy, which is an important risk factor for asthma and a potential modifier of the effects of air pollution. Mixed evidence exists on the latter, with two studies showing enhanced ${ }^{11} 14$ and two studies showing attenuated ${ }^{12} 13$ effects of exposure to $\mathrm{NO}_{2}$ in people with atopy or allergy.

The dispersion models used to assess $\mathrm{NO}_{2}$ levels have been validated $^{32-34}$ and applied. ${ }^{28} 2935$ The correlations between modelled and measured $\mathrm{NO}_{2}$ concentrations at 204 locations in Copenhagen (1994-1995), ${ }^{32}$ and in a busy street canyon in Copenhagen (1995-2006), ${ }^{33}$ were high $(r=0.90$ and 0.67, respectively). Thus, the model predicted both geographical and temporal variation well. We do not have data for validation of the model in the early period (before 1994), but the weaker associations observed with the 15-year $\mathrm{NO}_{2}$ mean (since 1991) than with the 35-year $\mathrm{NO}_{2}$ mean (since 1971) with asthma (online supplementary table W2) and $\mathrm{COPD}^{28}$ suggest the validity of the predicted $\mathrm{NO}_{2}$ levels from the 1970s and 1980s. Although the modelled concentrations are only surrogates of real exposure and are inevitably associated with some exposure misclassification, this is not likely to be different with respect to asthma hospitalisation. Further limitations of the exposure assessment method are that we assessed only outdoor concentrations and had no information on work address, commuting habits or personal activities.

Our study offers new evidence that long-term exposure to traffic-related air pollution in adult life is a risk factor for asthma hospitalisation among older people. The effect was most notable for those with the greatest propensity for admission, namely people with prior hospitalisations for asthma or COPD. Our study adds to the existing evidence that reductions in traffic emissions might also mitigate the asthma burden in older people.

Funding The study was funded by the Danish Research Council and Danish Cancer Society.

Competing interests None

Patient consent Obtained. 
Ethics approval Relevant Danish ethical committees and data protection agencies approved the study.

Provenance and peer review Not commissioned; externally peer reviewed.

\section{REFERENCES}

1. Eder W, Ege MJ, von Mutius E. The asthma epidemic. N Engl J Med 2006:355:2226-35.

2. Browatzki A, Ulrik CS, Lange P. Prevalence and severity of self-reported asthma in young adults, 1976-2004. Eur Respir J 2009;34:1046-51.

3. Gibson PG, McDonald VM, Marks GB. Asthma in older adults. Lancet 2010;376:803-13

4. Bahadori K, Doyle-Waters MM, Marra C, et al. Economic burden of asthma: a systematic review. BMC Pulm Med 2009;9:24.

5. FitzGerald JM, Quon BS. The impact of asthma guidelines. Lancet 2010:376:751-3.

6. Harver A, Kotses H. Asthma, Health and Society. A Public Health Perspective. New York: Springer, 2010.

7. Oftedal B, Nystad W, Brunekreef B, et al. Long-term traffic-related exposures and asthma onset in schoolchildren in Oslo, Norway. Environ Health Perspect 2009;117:839-44.

8. Gehring $\mathbf{U}$, Wijga $\mathrm{AH}$, Brauer $\mathrm{M}$, et al. Traffic-related air pollution and the development of asthma and allergies during the first 8 years of life. Am J Respir Crit Care Med 2010;181:596-603.

9. McConnell R, Islam T, Shankardass K, et al. Childhood incident asthma and trafficrelated air pollution at home and school. Environ Health Perspect 2010;118:1021-6.

10. Lindgren A, Stroh E, Nihlén $U$, et al. Traffic-related air pollution associated with prevalence of asthma and COPD/chronic bronchitis. A cross-sectional study in Southern Sweden. Int J Health Geogr 2009;8:2

11. Modig L, Jarvholm E, Ronnmark E, et al. Vehicle exhaust exposure in an incident case-control study of adult asthma. Eur Respir J 2006;28:75-81.

12. Modig L, Toren K, Janson C, et al. Vehicle exhaust outside the home and onset of asthma among adults. Eur Respir J 2009;33:1261-7.

13. Jacquemin $\mathbf{B}$, Sunyer J, Forsberg $\mathrm{B}$, et al. Home outdoor $\mathrm{NO}_{2}$ and new onset of self-reported asthma in adults. Epidemiology 2009;20:119-26.

14. Künzli N, Bridevaux PO, Liu LJ, et al; Swiss Cohort Study on Air Pollution and Lung Diseases in Adults. Traffic-related air pollution correlates with adult-onset asthma among never-smokers. Thorax 2009:64:664-70

15. Downs SH, Schindler C, Liu LJ, et al; SAPALDIA Team. Reduced exposure to $\mathrm{PM}_{10}$ and attenuated age-related decline in lung function. $N$ Engl $\mathrm{J}$ Med 2007;357:2338-47.

16. Schindler C, Keidel D, Gerbase MW, et al; SAPALDIA Team. Improvements in $\mathrm{PM}_{10}$ exposure and reduced rates of respiratory symptoms in a cohort of Swiss adults (SAPALDIA). Am J Respir Crit Care Med 2009;179:579-87.

17. Tjønneland A, Olsen A, Boll K, et al. Study design, exposure variables, and socioeconomic determinants of participation in Diet, Cancer and Health: a populationbased prospective cohort study of 57,053 men and women in Denmark. Scand J Public Health 2007;35:432-41.
18. Jensen SS, Berkowicz R, Hansen SH, et al. A Danish decision-support GIS tool for management of urban air quality and human exposures. Transportation Research Part D: Transport and Environment 2001;6:229-41.

19. Dykewicz MA. Occupational asthma: current concepts in pathogenesis, diagnosis, and management. J Allergy Clin Immunol 2009;123:519-28.

20. Pekkanen J, Sunyer J. Problems in using incidence to analyze risk factors in follow-up studies. Eur J Epidemiol 2008;23:581-4.

21. Contoli M, Papi A. When asthma diagnosis becomes a challenge. Eur Respir J 2010;36:231-3.

22. Jensen Aø, Nielsen GL, Ehrenstein V. Validity of asthma diagnoses in the Danish National Registry of Patients, including an assessment of impact of misclassification on risk estimates in an actual dataset. Clin Epidemiology 2010:2:67-72.

23. Wegmann M, Fehrenbach A, Heimann S, et al. NO2-induced airway inflammation is associated with progressive airflow limitation and development of emphysema-like lesions in C57bl/6 mice. Exp Toxicol Pathol 2005:56:341-50.

24. Hogg JC, van Eeden S. Pulmonary and systemic response to atmospheric air pollution. Respirology 2009:14:336-46.

25. Salvi SS, Nordenhall C, Blomberg A, et al. Acute exposure to diesel exhaust increases IL-8 and GRO-alpha production in healthy human airways. Am J Respir Crit Care Med 2000:161:550-7.

26. McCreanor J, Cullinan P, Nieuwenhuijsen MJ, et al. Respiratory effects of exposure to diesel traffic in persons with asthma. $N$ Engl J Med 2007:357:2348-58.

27. Andersen ZJ, Wåhlin P, Raaschou-Nielsen 0 , et al. Size distribution and tota number concentration of ultrafine and accumulation mode particles and hospita admissions in children and elderly in Copenhagen, Denmark. Occup Environ Med 2008;67:458-66

28. Andersen ZJ, Hvidberg M, Jensen SS, et al. Chronic obstructive pulmonary disease and long-term exposure to traffic-related air pollution: a cohort study. Am J Respir Crit Care Med 2011;183:455-61.

29. Raaschou-Nielsen 0, Andersen ZJ, Hvidberg M, et al. Lung cancer incidence and long-term exposure to air pollution from traffic. Environ Health Perspect 2011:119:860-5

30. James AL, Palmer LJ, Kicic E, et al. Decline in lung function in the Busselton Health Study: the effects of asthma and cigarette smoking. Am J Respir Crit Care Med 2005:171:109-14.

31. Gibson PG, Simpson JL. The overlap syndrome of asthma and COPD: what are its features and how important is it? Thorax 2009;64:728-35.

32. Berkowicz R, Ketzel $M$, Jensen JJ, et al. Evaluation and application of OSPM for traffic pollution assessment for large number of street locations. Environ Model Software 2008;23:296-303.

33. Ketzel M, Berkowicz R, Hvidberg M et al. Evaluation of AirGIS-a Gis based air pollution and human exposure modelling system. Int $J$ Environ Poll (In press).

34. Kakosimos KE, Hertel O, Ketzel M, et al. Operational Street Pollution Model (OSPM) - a review of performed application and validation studies, and future prospects. Environ Chem 2010; 7:485-503.

35. Jensen SS, Larson T, Deepti KC, et al. Modeling traffic air pollution in street canyons in New York City for intra-urban exposure assessment in the US Multi-Ethnic study of atherosclerosis and air pollution. Atmos Environ 2009;43:4544-56.

\section{Thorax alerts}

Sign up for our electronic table of contents alerts and you will never miss new issues of Thorax when published online. Stay ahead and up to date by visiting thorax.bmj.com. 